\title{
Patterns of spinal cord atrophy in HTLV-1 associated myelopathy/ tropical spastic paraparesis (HAM/TSP)
}

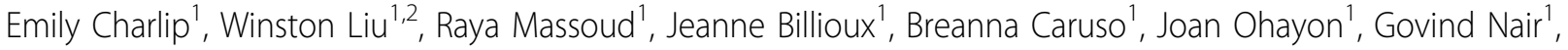 \\ Steven Jacobson ${ }^{1 *}$
}

From 17th International Conference on Human Retroviruses: HTLV and Related Viruses

Trois llets, Martinique. 18-21 June 2015

Spinal cord inflammation and atrophy contribute to debilitating symptoms in HAM/TSP. We have developed a robust and fast algorithm to determine average crosssectional area in cervical (c-spine) and thoracic (t-spine) spinal cords by tracing contours perpendicular to the edge in T1-weighted MRI images. The cross-sectional areas in the c- and $\mathrm{t}$-spines were determined in 25 $\mathrm{HAM} / \mathrm{TSP}, 10$ asymptomatic carriers (AC) and 10 healthy volunteer (HV) subjects. To date, we have followed 8 of the HAM/TSP patients longitudinally over a two-year period. When compared to the HV data, the HAM/TSP spinal cord profiles fell into four general categories: atrophic entire spine (48\%), atrophic t-spine $(32 \%)$, atrophic c-spine (8\%), and normal $(12 \%)$. The majority of ACs had similar spinal cord profiles to those in the HV group, however, 3 ACs showed a pattern similar to HAM/TSP. As a group, both HAM/TSP cand $\mathrm{t}$-spines were significantly lower than those of $\mathrm{HV}$ $(\mathrm{p}<0.01)$. In the 8 patients with follow-up scans, spinal cord size showed an overall decreasing trend over time. In a rapidly progressing patient with the shortest disease duration, we could estimate spinal cord atrophy at a rate of $11 \%$ a year in the thoracic cord. In addition, change in proviral load negatively correlated with change in both $\mathrm{c}$ - and $\mathrm{t}$-spine cross-sectional area $(p<0.05)$ for patients with shorter disease duration and increasing proviral loads (i.e. an increase in proviral load was associated with a more atrophic cord). These results suggest that the pattern of spinal cord tissue damage is specific to the underlying inflammatory disease, a

\footnotetext{
*Correspondence: JacobsonS@ninds.nih.gov

'Neuroimmunology Branch, National Institute of Neurological Disorders and Stroke, NIH, Bethesda, MD, USA

Full list of author information is available at the end of the article
}

finding that has direct implications for the use of average cross-sectional spinal cord area as a surrogate end point for clinical trials.

\section{Authors' details}

${ }^{1}$ Neuroimmunology Branch, National Institute of Neurological Disorders and Stroke, NIH, Bethesda, MD, USA. ²Fischell Department of Bioengineering, University of Maryland, College Park, MD, USA.

Published: 28 August 2015

doi:10.1186/1742-4690-12-S1-P32

Cite this article as: Charlip et al.: Patterns of spinal cord atrophy in HTLV-1 associated myelopathy/ tropical spastic paraparesis (HAM/TSP). Retrovirology 2015 12(Suppl 1):P32.
Submit your next manuscript to BioMed Central and take full advantage of:

- Convenient online submission

- Thorough peer review

- No space constraints or color figure charges

- Immediate publication on acceptance

- Inclusion in PubMed, CAS, Scopus and Google Scholar

- Research which is freely available for redistribution
() Biomed Central 